\title{
Comparison of the experimental results with the Langmuir and Freundlich models for copper removal on limestone adsorbent
}

\author{
Thair Sharif Khayyun ${ }^{1} \cdot$ Ayad Hameed Mseer $^{1}$
}

Received: 5 November 2018 / Accepted: 9 October 2019 / Published online: 14 October 2019

(c) The Author(s) 2019

\begin{abstract}
The purpose of this study was to investigate the possibility of the limestone as an adsorbed media and low-cost adsorbent. Batch adsorption studies were conducted to examine the effects of the parameters such as initial metal ion concentration $C_{0}$, particle size of limestone $D_{\mathrm{L}}$, adsorbent dosage and equilibrium concentration of heavy metal $C_{\mathrm{e}}$ on the removal of the heavy metal $(\mathrm{Cu})$ from synthetic water solution by limestone. The removal efficiency is increased with the increase in the volume of limestone (influenced by the media specific area). It has been noted that the limestone with diameter of 3.75 is the most effective size for removal of copper from synthetic solution. The adsorption data were analyzed by the Langmuir and Freundlich isotherm model. The average values of the empirical constant and adsorption constant (saturation coefficient) for the Langmuir equation were $a=0.022 \mathrm{mg} / \mathrm{g}$ and $b=1.46 \mathrm{l} / \mathrm{mg}$, respectively. The average values of the Freundlich adsorption constant and empirical coefficient were $K_{\mathrm{f}}=0.010 \mathrm{mg} / \mathrm{g}$ and $n=1.58 \mathrm{l} / \mathrm{mg}$, respectively. It was observed that the Freundlich isotherm model described the adsorption process with high coefficient of determination $R^{2}$, better than the Langmuir isotherm model and for low initial concentration of heavy metal. Also, when the values of amount of heavy metal removal from solution are predicted by the Freundlich isotherm model, it showed best fits the batch study. It is clear from the results that heavy metal $(\mathrm{Cu})$ removal with the limestone adsorbent appears to be technically feasible and with high efficiency.
\end{abstract}

Keywords Limestone $\cdot$ Heavy metal $(\mathrm{Cu}) \cdot$ Langmuir $\cdot$ Freundlich $\cdot$ Batch studies

\section{Introduction}

Removal of heavy metals from aqueous solution is necessary because of the frequent appearance of these metals in waste streams from many industries, including electroplating, metal finishing, metallurgical, tannery, chemical manufacturing, mining and battery manufacturing. In recent years, this problem has received considerable attention, because available heavy metals in the waste streams can be readily adsorbed by marine animals which directly enter the human food chain presenting a high health risk to consumers.

Tito et al. (2008) investigated the removal of $\mathrm{Zn}^{2+}$ from aqueous solution by using bentonite clay. The results of his study showed that Langmuir equation is adequate to describe

Thair Sharif Khayyun

thshkhma@yahoo.com

Ayad Hameed Mseer

ayad_mseer@yahoo.com

1 Building and Constructions Engineering Department, University of Technology, Baghdad, Iraq zinc adsorption at different $\mathrm{pH}$ values and particles size of bentonite clay. Zinc adsorption in bentonite clay depends on both $\mathrm{pH}$ and particle size, where it decreases as they increase. The maximum retention capacity, $3.24 \mathrm{mg} / \mathrm{g}$, was obtained in $\mathrm{pH} 4$ using a particle size of bentonite clay less than $0.5 \mathrm{~mm}$.

Mohan and Chander (2006) investigated the removal of $\mathrm{Fe}(\mathrm{II})$ from aqueous media by using chitosan and the adsorbent in both batch and continuous system. Batch experiments were carried out at initial concentration range of $10-50 \mathrm{mg} / \mathrm{l}$ and temperature range of $20-40{ }^{\circ} \mathrm{C}$. Adsorption equilibrium data were well-fitted with Langmuir-Freundlich model, and the model parameters were recovered. The results of the study in batch experiments showed that the maximum adsorption capacity of $28.7 \mathrm{mg} / \mathrm{g}$ and removal efficiency of 93\% was obtained.

Abu El Hassan and Sawsan (2014) showed the removal of some heavy metals ions $\left(\mathrm{Hg}^{2+}, \mathrm{Pb}^{2+}\right.$ and $\left.\mathrm{Zn}^{2+}\right)$ from aqueous solution and $\left(\mathrm{Mn}^{2+}, \mathrm{Ca}^{2+}\right)$ ions by adsorption process. The commercial activated carbon, silica and ceramic were used as adsorbents. The adsorption process was carried out at a 
$\mathrm{pH}$ which ranges from 5.3 to 5.5 at room temperature. The results of this work showed that $100 \%$ adsorption uptake was obtained in some cases.

$\mathrm{Li}$ (2008) conducted three separate experiments to assess heavy metal removal from metal aqueous solutions and synthetic landfill leachate by adsorption using low-cost natural adsorbents. Fundamental batch investigations indicated that the 4.0-4.75 mm crushed mollusk shells and the Sphagnum peat moss were the best adsorbents for cadmium and nickel removal, respectively. The results indicated that $47.9 \%$ and $42.7 \%$ cadmium and nickel removal efficiencies could be obtained under these operational conditions, respectively. The flow rate applied in this operation was $1.5 \mathrm{ml} / \mathrm{min}$ (surface loading of $27.52 \mathrm{~cm}^{3} / \mathrm{cm}^{2}$ day). Peat was found to have the best adsorption capacities in columns treating aerated synthetic leachate for cadmium (78.6\%) and nickel (83.8\%) removal efficiencies.

The objective of this study is to evaluate the efficiency of limestone adsorbent to be as adsorbed media to adsorb heavy metal $(\mathrm{Cu})$ from aqueous solution as alternative media of the existing commercial adsorbents.

\section{Adsorption isotherm and sorption efficiency}

\section{Adsorption isotherm}

Two adsorption isotherm models used frequently are the Langmuir and Freundlich.

The Langmuir model was originally proposed to describe adsorption of gas molecules onto homogeneous solid surfaces (crystalline materials) that exhibit one type of adsorption site as in Langmuir (1918). Many investigators have tacitly extended the Langmuir adsorption model to describe adsorption of solution species onto solid adsorbents including heterogeneous solids such as soils as in Wilhelm (1999). The Langmuir model for adsorption is:

$q_{\mathrm{e}}=\frac{a b C_{\mathrm{e}}}{1+b C_{\mathrm{e}}}$

where $q_{\mathrm{e}}=$ amount of adsorbate adsorbed per unit mass of solid (mg/g), $b=$ Langmuir adsorption constant related to the energy of adsorption $(1 / \mathrm{mg}), a=$ maximum adsorption capacity of the solid $(\mathrm{mg} / \mathrm{g}), C_{\mathrm{e}}=$ equilibrium solution concentration of the adsorbate $(\mathrm{mg} / \mathrm{l})$.

The Freundlich isotherm model as in Freundlich (1926) is defined as:

$q_{\mathrm{e}}=K_{\mathrm{f}} C_{\mathrm{e}}^{1 / n}$

where $q_{\mathrm{e}}=$ amount of adsorbate adsorbed per unit mass of solid, $C_{\mathrm{e}}=$ equilibrium solution concentration of the adsorbate, $K_{\mathrm{f}}=$ Freundlich adsorption constant, $n=$ empirical constant.
Because adsorption isotherms at very low solute concentrations are often linear, either the Freundlich isotherm with $(1 / n)$ equaling (1) or the Langmuir isotherm with $\left(b C_{\mathrm{e}}\right)$ much greater than 1 fits the data. The value of $(1 / n)$ for the adsorption of many radionuclides is often significantly different from 1 , such that nonlinear isotherms are observed as in Wilhelm (1999).

The constant partition coefficient, $K_{\mathrm{d}}$, is a measure of sorption and is defined as the ratio of the quantity of the adsorbate (i.e., metal or radionuclide) adsorbed per unit mass of solid to the quantity of the adsorbate remaining in solution at equilibrium. For the reaction:

$q+C_{\mathrm{e}}=q_{\mathrm{e}}$

the mass action expression for $K_{\mathrm{d}}$ (typically in units of $\mathrm{ml} / \mathrm{g}$ ) is:

$K_{\mathrm{d}}=q_{\mathrm{e}} / C_{\mathrm{e}}$

where $q=$ free or unoccupied surface adsorption sites, $C_{\mathrm{e}}=$ total dissolved adsorbate remaining in solution at equilibrium $(\mu \mathrm{g} /$ $\mathrm{ml})$, and $q_{\mathrm{e}}=$ adsorbate on the solid at equilibrium $(\mu \mathrm{g} / \mathrm{g})$.

Describing the $K_{\mathrm{d}}$ in terms of this simple reaction assumes that $q$ is in great excess with respect to $C_{\mathrm{e}}$ and that the activity of $q_{\mathrm{e}}$ is equal to 1 . The $K_{\mathrm{d}}$ term is valid only for a particular adsorbent and applies only to those aqueous chemical conditions (e.g., adsorbate concentration, solution/electrolyte matrix, temperature) in which it was measured. Also inherent in the $K_{\mathrm{d}}$ term are the assumptions that the system is reversible and is independent of the adsorbate concentration in the aqueous phase.

\section{Sorption efficiency}

The values of percent metal uptake by the sorbent (sorption efficiency) and the amount of metal ion adsorbed have been calculated using the following relationships:

Sorption efficiency $=\frac{C_{0}-C_{\mathrm{e}}}{C_{0}} * 100 \%$

$q_{\mathrm{e}}=\left(C_{0}-C_{\mathrm{e}}\right) * v / m$

where $C_{0}=$ initial concentration of metal ion in the solution $(\mathrm{mg} / \mathrm{l}), C_{\mathrm{e}}=$ final concentration of metal ion in the solution $(\mathrm{mg} / \mathrm{l}), m=$ mass of adsorbent $(\mathrm{g} / \mathrm{l}), v=$ volume of solution (l).

\section{Materials and methods}

\section{Limestone}

Commercially, limestone types used to conduct experiments are obtained from Al-Anbar city which is located 
Table 1 Different sizes of roughing filter media as in Wegelin (1996)

\begin{tabular}{llll}
\hline $\begin{array}{l}\text { Roughing filter } \\
\text { description }\end{array}$ & $\begin{array}{l}\text { First compart- } \\
\text { ment }(\mathrm{mm})\end{array}$ & $\begin{array}{l}\text { Second compart- } \\
\text { ment }(\mathrm{mm})\end{array}$ & $\begin{array}{l}\text { Third com- } \\
\text { partment } \\
(\mathrm{mm})\end{array}$ \\
\hline Course & $24-16$ & $18-12$ & $12-8$ \\
Normal & $18-12$ & $12-8$ & $8-4$ \\
Fine & $12-8$ & $8-4$ & $4-2$ \\
\hline
\end{tabular}

(110) $\mathrm{km}$ west of Baghdad-Iraq. In this research, two types of limestone have been used, western red and northern white in three different sizes which are classified according to the experience of the sieve analysis conducted on them. As a result of the sieve analysis tests conducted on the limestone, the adopted three sizes of diameter of limestone are $3.75 \mathrm{~mm}$ (western red) and 5.0, $9.5 \mathrm{~mm}$ (northern white), respectively, which were used in this research.

Common grades of media used in roughing filters are provided as in Wegelin (1996) and shown in Table 1. Due to this table, the limestone used in this research has been considered as fine grade limestone.

In this study, a compacted sample has been used which is vacuum sealed inside a plastic bag. The density of the sample, SG1, is calculated using a water displacement method, with the sample sealed. With the sample still in water, the bag is cut open. Since the sample is under vacuum and the air voids are evacuated, water will rush into fill all the water accessible air voids in the compacted sample. With the saturated weight of sample known, an apparent maximum density, SG2, can be calculated. The difference between SG2 and SG1 is the measure of the amount of water that has penetrated the compacted sample. This difference can be used to determine the fraction of total number of voids that are accessible to water, effective percent porosity or percent effective air voids. The results obtained from this method can be used to determine the percentage of total air voids in a compacted sample that can be filled with water through surface or interconnected paths within the sample. These results are listed in Table 2.

Reference (ASTM C568) classifies limestone into three categories based on the bulk density of the limestone as shown in Table 3.

As a result of the density analysis test conducted on the chosen limestone and compare it with ASTM C568, "Standard Specification for Limestone Dimension Stone," it is shown that the used limestone has been within the limited standard (low density).

Many industrial applications of limestone constrain on the levels of specific impurities (such as $\mathrm{SiO}_{2}, \mathrm{MgO}$ and $\mathrm{Fe}_{2} \mathrm{O}_{3}$ ), and therefore, chemical analysis of limestone raw material is necessary to assess the grade of the stone.
Table 2 Experimental conditions for the limestone used in the present study

\begin{tabular}{|c|c|c|c|}
\hline Rock type & Western Red No. 2 & $\begin{array}{l}\text { Northern } \\
\text { White } \\
\text { No. } 2\end{array}$ & $\begin{array}{l}\text { Northern } \\
\text { White } \\
\text { No. } 3\end{array}$ \\
\hline Solid weight (g) & 240 & 245 & 220 \\
\hline $\begin{array}{l}\text { (Solid + water) } \\
\text { weight }(\mathrm{g})\end{array}$ & 313 & 323 & 310 \\
\hline Water weight (g) & 73 & 78 & 90 \\
\hline Container volume(L) & 0.2 & 0.2 & 0.2 \\
\hline Void volume(L) & 0.073 & 0.078 & 0.09 \\
\hline Solid volume(L) & 0.127 & 0.122 & 0.11 \\
\hline Porosity & 0.365 & 0.39 & 0.45 \\
\hline Void ratio & 0.575 & 0.639 & 0.818 \\
\hline Density $\left(\mathrm{kg} / \mathrm{m}^{3}\right)$ & 1889.8 & 2008.2 & 2000 \\
\hline
\end{tabular}

Table 3 Standard specification for limestone dimension stone as in Ref. ASTM C568

\begin{tabular}{lll}
\hline Classification No. & Consistency degree & Density $\left(\mathrm{kg} / \mathrm{m}^{3}\right)$ \\
\hline Class I & Low density & $1760-2160$ \\
Class II & Medium density & $2160-2560$ \\
Class III & High density & $>2560$ \\
\hline
\end{tabular}

Table 4 Chemical characterization of the limestone used in the present study

\begin{tabular}{lcc}
\hline Components & Western Red & Northern White \\
\hline Lime $(\mathrm{CaO}) \%$ & 46.28 & 53.00 \\
Silica $\left(\mathrm{SiO}_{2}\right) \%$ & 6.88 & 2.12 \\
Alumina $\left(\mathrm{Al}_{2} \mathrm{O}_{3}\right) \%$ & 0.88 & 0.44 \\
$\mathrm{MgO} \%$ & 4.2 & 1.0 \\
$\mathrm{Fe}_{2} \mathrm{O}_{3} \%$ & 0.45 & 0.35 \\
Loss on ignition (LOI) (\%) & 40.64 & 41.91 \\
Purity & 88.47 & 96.53 \\
\hline
\end{tabular}

However, the carbonate content of limestone is fundamental in most industrial uses and a simple laboratory method for determining this component is a valuable procedure for determining chemical purity. Ideally, the method should be rapid, simple, accurate and capable of giving reproducible results. Chemical characterization of the limestone used in the copper removal process used in this research is described in Table 4. The determination of carbonate content can be used to classify chemical-grade limestone, Table 5 as in Bloodworth (2002). The classification of limestone used in this research is as a medium purity for northern white limestone and low purity for western red limestone. Such a definition of chemical purity is relatively simple and can easily illustrate the distribution of limestone purity on a map.

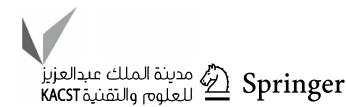


This classification is also suitable for comparison of chemical data for limestone of different geological origin. The typical chemical analysis of limestone will include $\mathrm{CaO}$, $\mathrm{MgO}, \mathrm{SiO}_{2}, \mathrm{Al}_{2} \mathrm{O}_{3}, \mathrm{Na}_{2} \mathrm{O}, \mathrm{K}_{2} \mathrm{O}, \mathrm{P}_{2} \mathrm{O}_{5}, \mathrm{MnO}$ and $\mathrm{S}, \mathrm{F}, \mathrm{Cu}$, $\mathrm{Pb}$ and $\mathrm{Zn}$.

\section{Copper solution preparation}

A synthetic water has been prepared by mixing the effluent from the water tank with the highest solubility copper compound (copper nitrate) in three different concentrations $(40 \mathrm{mg} / \mathrm{L}, 24 \mathrm{mg} / \mathrm{L}$ and $8 \mathrm{mg} / \mathrm{L})$. A synthetic wastewater has been prepared by dissolving (1,3 and 5) g of copper nitrate into 1251 of water tank and mixed well for a homogeneous solution and to ensure melting of copper nitrate in water. Atomic absorption spectroscopy (AAS) was used for the quantitative determination of chemical elements employing the absorption of optical radiation (light) by free atoms in the gaseous state. In analytical chemistry, the technique is used for determining the concentration of a particular element $(\mathrm{Cu})$ in a sample to be analyzed. AAS can be used to determine over 70 different elements in solution or directly in solid samples.

\section{Batch experiment}

The batch study has been conducted to establish the removal pattern of heavy metals using limestone. In this experiment, different volumes of limestone calculated based on the weight $20,60,100,140$ and $180 \mathrm{~g}$ are used in a specific volume of heavy $\mathrm{Cu}$ solution ( $120 \mathrm{ml}$ of synthetic Cu solution) which are kept in polyethylene bottles. The experiment has been conducted at different $\mathrm{Cu}$ concentrations $(40,24$, and $8 \mathrm{mg} / \mathrm{L}$ ), which is shaken by an orbital shaker at $300 \mathrm{rpm}$ for $60 \mathrm{~min}$, which it allows for all the surface area of the adsorbent to come in contact with the model water containing heavy metals. Afterward, the solution has then been left to settle for $90 \mathrm{~min}$ before testing $\mathrm{Cu}$ concentration by an atomic absorption spectrophotometer.

Table 5 Classification of limestone by calcium carbonate content as in Bloodworth (2002)

\begin{tabular}{ll}
\hline Category & Percentage $\mathrm{CaCO}_{3}$ \\
\hline Very high purity & $>98.5$ \\
High purity & $98.5-97.0$ \\
Medium purity & $97.0-93.5$ \\
Low purity & $93.5-85.0$ \\
Impure & $<85.0$ \\
\hline
\end{tabular}

\section{Results and discussion}

\section{Effect of volume of limestone on removal efficiency of copper}

In this section, batch studies are used to remove $\mathrm{Cu}$ from water. The removal of $\mathrm{Cu}$ against media weight at different metal concentrations 7.04, 4.39 and $1.72 \mathrm{ppm}$, for the three sizes of limestone and for each value of solution is shown in Figs. 1, 2 and 3. The removal efficiencies have been calculated as a result of changing the volume of limestone (calculated based on the weight) within constant volume solution of $125 \mathrm{ml}$. These weights are 20,60,100, 140 and $180 \mathrm{~g}$, respectively. It has been shown that for each concentration, the removal efficiency is increased with the increase in the volume of limestone (calculated based on the weight) within constant volume solution $(125 \mathrm{ml})$. This indicates that the removal of copper has been influenced by the media specific area (surface area).

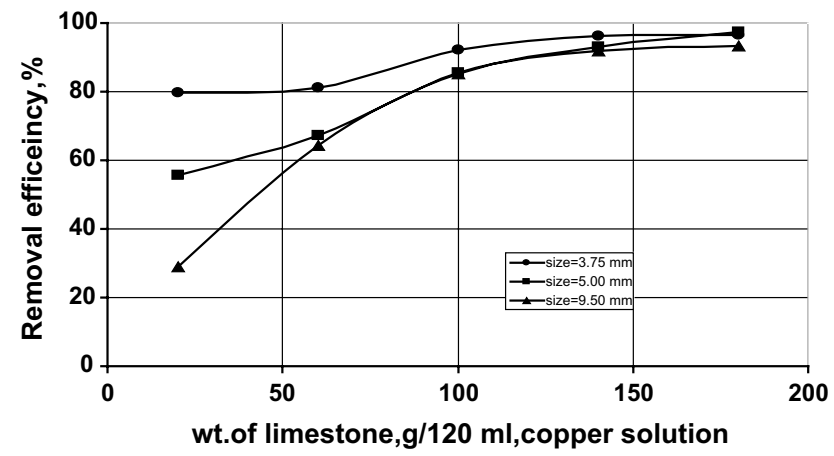

Fig. 1 The effect of volume of limestone on removal efficiency of copper for high influent concentration of copper (7.04 mg/l)

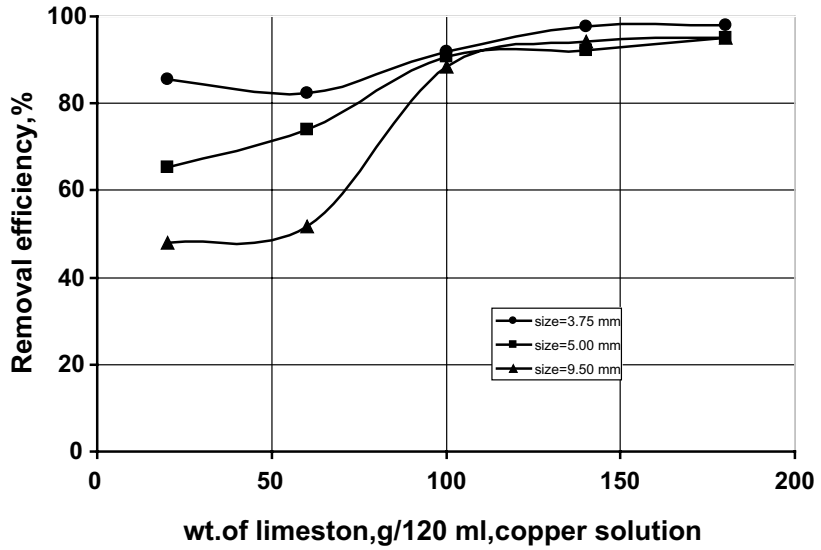

Fig. 2 The effect of volume of limestone on removal efficiency of copper for middle influent concentration of copper $(4.39 \mathrm{mg} / \mathrm{l})$ 


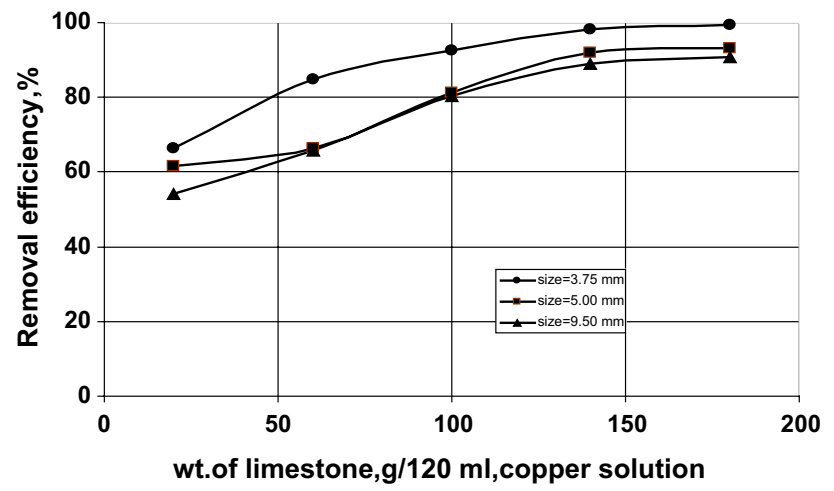

Fig. 3 The effect of volume of limestone on removal efficiency of copper for low influent concentration of copper $(1.72 \mathrm{mg} / \mathrm{l})$

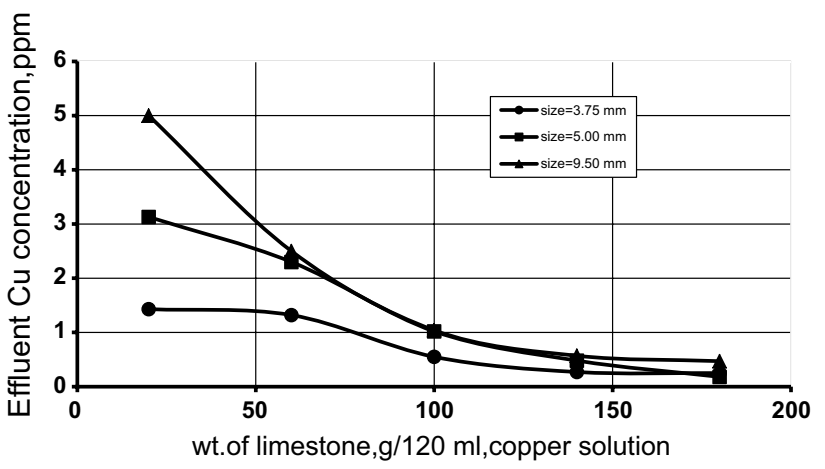

Fig. 4 The effect of volume of limestone on effluent copper concentration for high influent concentration of copper $(7.04 \mathrm{mg} / \mathrm{l})$

A trend of increment in efficiency capacity with increment in adsorbent dosage is observed, and the maximum efficiency is at weight of $180 \mathrm{~g}$ used in this experiment. The increment in adsorption capacity with increase in adsorbent dosage has been expected, since number of adsorbent particles increases, and thus, more surface areas were available for metals attachment. It is plausible to suggest that with higher dosage of adsorbent, there would be great availability of exchangeable sites for metal ions.

\section{Effect of volume of limestone on effluent copper concentration}

The increase in the removal efficiency which has been mentioned in the previous paragraph means that naturally decrease in the amount of the effluent copper concentration, because of adsorbing the largest amount of it within the adsorbent material which in the same time shows high efficiency, Figs. 4, 5 and 6. These results indicated that limestone is potentially useful as an alternative filter with its cost is low.

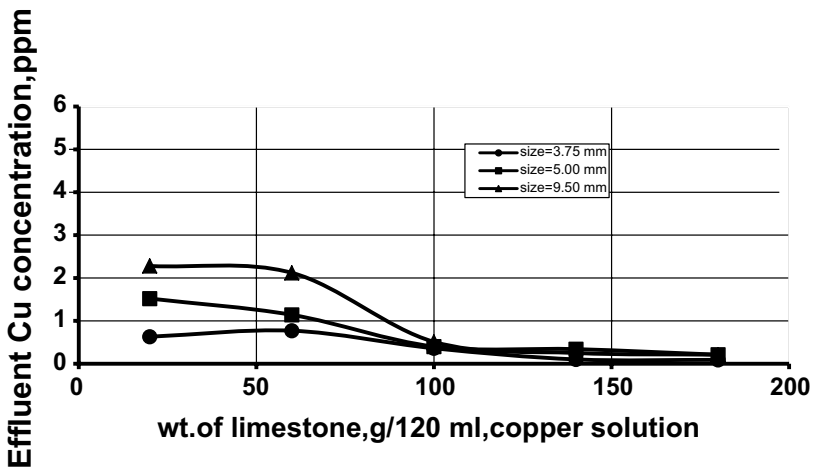

Fig. 5 The effect of volume of limestone on effluent copper concentration for middle influent concentration of copper $(4.39 \mathrm{mg} / \mathrm{l})$

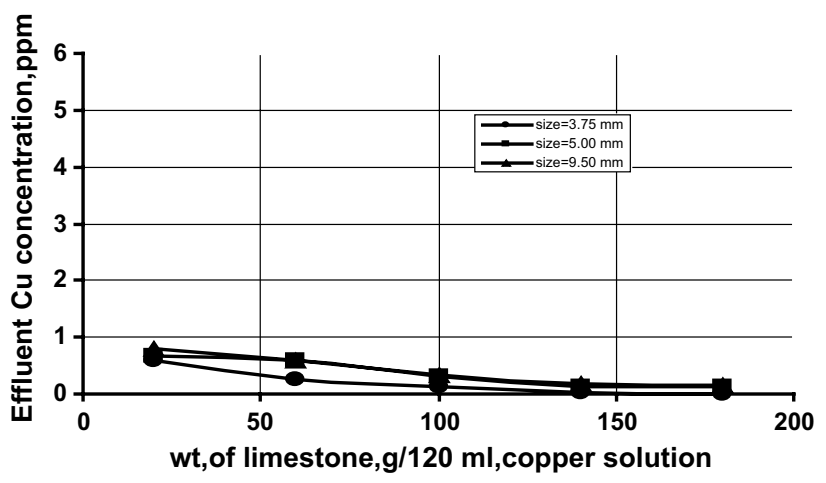

Fig. 6 The effect of volume of limestone on effluent copper concentration for low influent concentration of copper $(1.72 \mathrm{mg} / \mathrm{l})$

Table 6 Ranges of removal efficiency for different sizes of limestone and influent copper concentrations

\begin{tabular}{llll}
\hline Dia. $(\mathrm{mm})$ & \multicolumn{4}{l}{ Influent copper concentration $(\mathrm{mg} / \mathrm{L})$} \\
\cline { 2 - 4 } & $7.04(\%)$ & $4.39(\%)$ & $1.72(\%)$ \\
\hline 3.75 & $79.68-96.44$ & $85.64-97.94$ & $66.27-99.41$ \\
5.00 & $55.53-97.44$ & $65.37-95.21$ & $61.62-93.02$ \\
9.50 & $28.97-93.32$ & $48.06-95.16$ & $54.06-90.69$ \\
\hline
\end{tabular}

\section{Effective size of limestone in batch studies}

The removal efficiencies were tested as a result of changing the influent concentration of copper for different size of limestone at different weights of limestone (20-180 g). It has been noted that the western red no. 2 limestone with diameter of $3.75 \mathrm{~mm}$ is the most effective size for removal of copper from synthetic solution, Table 6 . Also, it is noted that the behavior of the three types of limestone within the three different influent copper concentrations has not been the same and ranges from 90 to $99 \%$; this means there is a direct correlation between metal ion concentration and 
removal efficiency. So, there is a significant difference in removal rate with decreasing copper concentration from 7.04 to $1.72 \mathrm{ppm}$.

\section{Adsorption isotherm}

In Eq. (1), $q_{\mathrm{e}}$ is calculated from Eq. (6) and by using the data in batch study. Substituting $K$ for $\left(a^{*} b\right)$ in Eq. (1) and taking the reciprocal of Eq. (1) obtain a linear relationship and a plot of values for $1 / q_{\mathrm{e}}\left(y\right.$-axis) versus values of $1 / C_{\mathrm{e}}$ ( $x$-axis). Figure 7 shows the relationship between $1 / q_{\mathrm{e}}$ and $1 / C_{\mathrm{e}}$ for limestone size $(3.75 \mathrm{~mm})$ and $C_{0}(7.04 \mathrm{mg} / \mathrm{l})$. Then, one can determine the value of $K$ from the slope of the bestfit line and the value of ( $b$ and $a$ ) from the intercept. The data for Langmuir adsorption isotherm are given in Table 7. Regression analysis of the data is shown in Table 7, fitted well in Langmuir adsorption isotherm and for different initial concentrations and limestone sizes. The average values of the empirical constant and adsorption constant (saturation coefficient) for the Langmuir equation were $a=0.022 \mathrm{mg} / \mathrm{g}$ and $b=1.46 \mathrm{l} / \mathrm{mg}$, respectively. The adsorption isotherms at very low solute concentrations are often linear (high $R^{2}$ ), the Langmuir isotherm with $b^{*} C_{\mathrm{e}}$ much greater than 1 fits the data and approximately, and $q_{\mathrm{e}}$ is equal to $a$ (empirical constant or the maximum adsorption capacity of the solid).

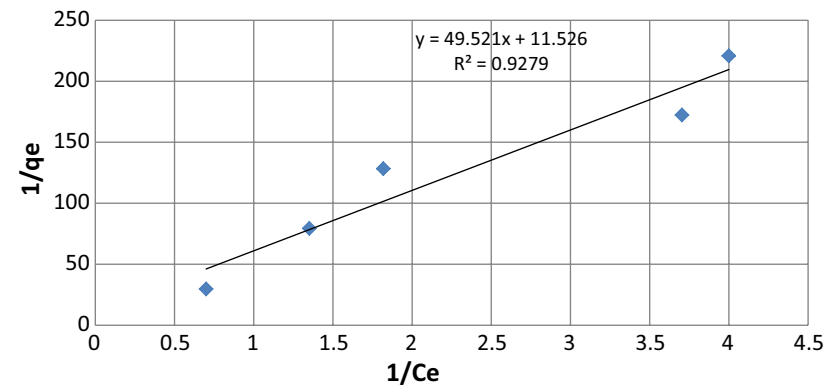

Fig. 7 Relationship between $1 / q_{\mathrm{e}}$ and $1 / C_{\mathrm{e}}$ of Langmuir equation for limestone size $(3.75 \mathrm{~mm})$ and $C_{0}(7.04 \mathrm{mg} / \mathrm{l})$
Figure 8 was used to examine the differences between $q_{\mathrm{e}}$ by Langmuir equation and $q_{\mathrm{e}}$ by the batch study. Results indicated that no statistically significant differences could be detected between these values using the statistical model.

In Eq. (2), the Freundlich equation is sometimes written with the exponent being $N$ instead of $1 / n$. The Freundlich isotherm can be transformed to a linear equation by taking the (Ln) of both sides of Eq. (2) as in Wilhelm (1999). When $\operatorname{Ln}\left(q_{\mathrm{e}}\right)$ is plotted on the $y$-axis and $\operatorname{Ln}\left(C_{\mathrm{e}}\right)$

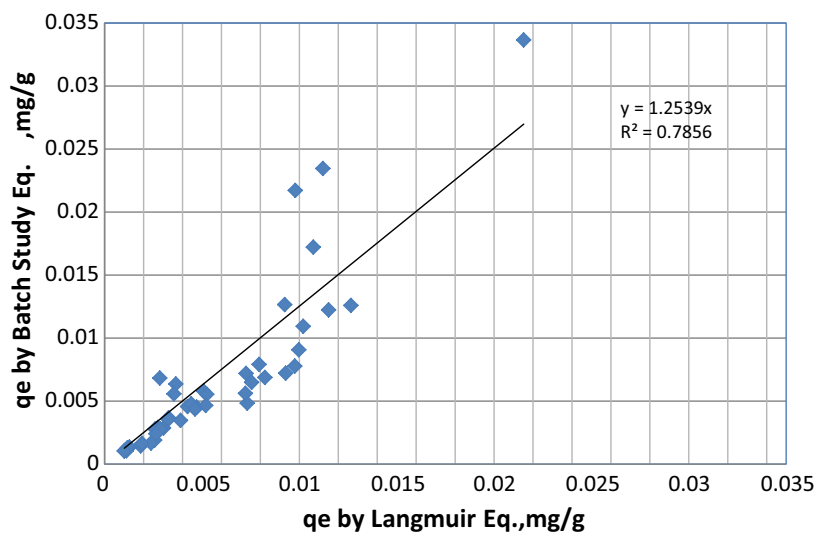

Fig. 8 Amount of heavy metal removal from solution by Langmuir equation and batch study equation

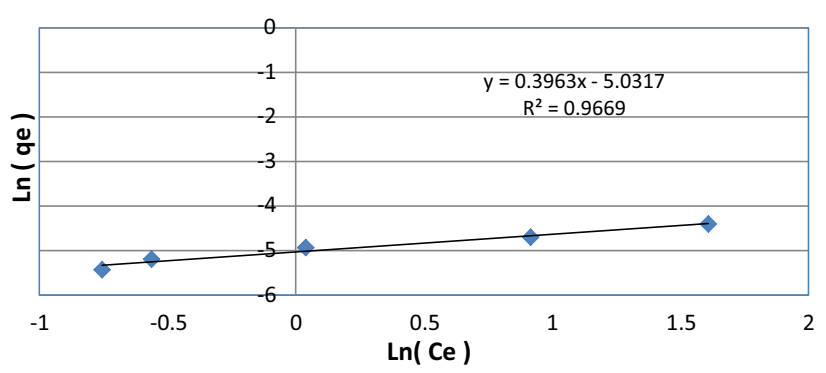

Fig. $9 \operatorname{Ln}\left(q_{\mathrm{e}}\right)$ versus $\operatorname{Ln}\left(C_{\mathrm{e}}\right)$ for Freundlich equation for limestone size $(9.5 \mathrm{~mm})$ and $C_{0}(1.72 \mathrm{mg} / \mathrm{l})$
Table 7 Calculated values for the different initial concentrations and Limestone sizes to plot Langmuir adsorption isotherm

\begin{tabular}{lllllll}
\hline Equation & $\begin{array}{l}\text { Limestone size } \\
(\mathrm{mm})\end{array}$ & $C_{0}(\mathrm{mg} / \mathrm{l})$ & $R^{2}$ & $K$ & $b$ & $a$ \\
\hline$Y=49.52 X+11.52$ & 3.75 & 7.04 & 0.927 & 0.020 & 0.230 & 0.087 \\
$Y=23.26 X+71.93$ & 3.75 & 7.04 & 0.832 & 0.043 & 3.093 & 0.014 \\
$Y=5.904 X+342.9$ & 3.75 & 7.04 & 0.732 & 0.169 & 57.95 & 0.003 \\
$Y=27.90 X+80.34$ & 5.00 & 4.39 & 0.740 & 0.036 & 2.892 & 0.012 \\
$Y=69.49 X+46.26$ & 5.00 & 4.39 & 0.933 & 0.014 & 0.648 & 0.022 \\
$Y=94.15 X+135.5$ & 5.00 & 4.39 & 0.872 & 0.011 & 1.491 & 0.007 \\
$Y=68.18 X+73.63$ & 9.50 & 1.72 & 0.972 & 0.015 & 1.104 & 0.014 \\
$Y=55.63 X+83.70$ & 9.50 & 1.72 & 0.947 & 0.018 & 1.507 & 0.012 \\
$Y=136.80 X+100.20$ & 9.50 & 1.72 & 0.933 & 0.007 & 0.701 & 0.010 \\
\hline
\end{tabular}


Table 8 Calculated values for the different initial concentrations and limestone sizes to plot Freundlich adsorption isotherm

\begin{tabular}{lllllll}
\hline Equation & $\begin{array}{l}\text { Limestone size } \\
(\mathrm{mm})\end{array}$ & $C_{0}(\mathrm{mg} / \mathrm{l})$ & $R^{2}$ & $N$ & $K_{\mathrm{f}}$ & $n$ \\
\hline$Y=1.055 X-3.950$ & 3.75 & 7.04 & 0.939 & 1.055 & 0.019 & 0.948 \\
$Y=0.761 X-4.051$ & 3.75 & 7.04 & 0.808 & 0.761 & 0.017 & 1.314 \\
$Y=0.396 X-5.125$ & 3.75 & 7.04 & 0.850 & 0.396 & 0.006 & 2.525 \\
$Y=0.546 X-4.661$ & 5.00 & 4.39 & 0.863 & 0.546 & 0.010 & 1.832 \\
$Y=0.853 X-4.641$ & 5.00 & 4.39 & 0.921 & 0.853 & 0.010 & 1.172 \\
$Y=0.907 X-4.975$ & 5.00 & 4.39 & 0.861 & 0.907 & 0.007 & 1.103 \\
$Y=0.396 X-5.031$ & 9.50 & 1.72 & 0.966 & 0.396 & 0.007 & 2.525 \\
$Y=0.572 X-4.954$ & 9.50 & 1.72 & 0.963 & 0.572 & 0.007 & 1.748 \\
$Y=0.943 X-5.189$ & 9.50 & 1.72 & 0.916 & 0.943 & 0.006 & 1.060 \\
\hline
\end{tabular}

with high $R^{2}$. Also, Fig. 10 indicates that no statistically significant differences could be detected between $q_{\mathrm{e}}$ values when it compares with Fig. 8.

The Freundlich isotherm only applies to data obtained at low values of $C_{\mathrm{e}}$ (concentration of contaminant in the equilibrium solution). Mckay et al. (1982) indicated that the value of $n$ between 2 and 10 is a good adsorption. The calculated $n$ value for the adsorption of copper was 1.58 showing good efficiency for copper adsorption by limestone adsorbent.

\section{Conclusions}

1. The removal efficiency of $(\mathrm{Cu})$ is increased with the increase in the volume of limestone. It has been influenced by the media specific area or the surface area.

2. The most effective size of limestone for removal of copper from synthetic solution is with a diameter of $3.75 \mathrm{~mm}$.

3. There is a significant difference in removal rate $(90$ 99\%) with decreasing copper concentration from 7.04 to $1.72 \mathrm{ppm}$.

4. The average values of the empirical constant and adsorption constant (saturation coefficient) for the Langmuir equation were $a=0.022 \mathrm{mg} / \mathrm{g}$ and $b=1.46 \mathrm{l} / \mathrm{mg}$, respectively.

5. The average values of the Freundlich adsorption constant and empirical coefficient were $K_{\mathrm{f}}=0.010 \mathrm{mg} / \mathrm{g}$ and $n=1.58 \mathrm{l} / \mathrm{mg}$, respectively.

6. It was observed that the Freundlich isotherm model described the adsorption process with high coefficient of determination $R^{2}$, better than the Langmuir isotherm model and for low initial concentration of heavy metal.

7. When the values of amount of heavy metal removal from solution are predicted by the Freundlich isotherm model, it showed best fits the batch study.

8. It is clear from the results that heavy metal $(\mathrm{Cu})$ removal with the limestone adsorbent appears to be technically feasible and with high efficiency. model is a better predicator than the Langmuir model 
Open Access This article is distributed under the terms of the Creative Commons Attribution 4.0 International License (http://creativecommons.org/licenses/by/4.0/), which permits unrestricted use, distribution, and reproduction in any medium, provided you give appropriate credit to the original author(s) and the source, provide a link to the Creative Commons license, and indicate if changes were made.

\section{References}

Abu El Hassan M, Sawsan M (2014) Adsorption of some heavy metals and $(\mathrm{Mg}, \mathrm{Ca})$ ions from aqueous solutions by using different environmental residuals as a cheap adsorbents at optimum conditions. Sci J Chem 2(1):1-5

ASTM C568. Standard specifications for limestone

Bloodworth AJ (2002) Industrial minerals laboratory manual. Technical Report WG/93/1

Freundlich H (1926) Adsorption in solution. Phys Chem 57:384-410

Langmuir I (1918) Adsorption of gases on plane surfaces of glass, mica and platinum. J Am Chem Soc 40:1361-1403

Li C (2008) Batch and bench-scale fixed-bed column evaluations of heavy metal removal from aqueous solutions and synthetic landfill leachate using low-cost natural adsorbents. Qweens University, Kingston

Mckay G, Blair HS, Gardner JK (1982) Adsorption of dyes on chitin equilibrium studies. J Appl Polym Sci 27:3043-3057

Mohan D, Chander S (2006) Single, binary and multicomponent sorption of iron and manganese on lignite. J Colloid Interface Sci 299:76-87

Tito GA, Chaves LHG, Souza RS (2008) Zinc adsorption in bentonite clay: particle size and $\mathrm{Ph}$ influence. Rev Caatinga 21(5):1-4

Wegelin M (1996) Surface water treatment by roughing filters: a design, construction and operation manual. Swiss Federal Institute for Environmental Science and Technology (EAWAG) and Department Water and Sanitation in Developing Countries (SANDEC), Dübendorf

Wilhelm RG (1999) Understanding variation in partition coefficient, $K_{\mathrm{d}}$, values, vol 1. Environmental Protection Agency (EPA), Washington, DC

Publisher's Note Springer Nature remains neutral with regard to jurisdictional claims in published maps and institutional affiliations. 